\title{
64. EFFECT OF HYDROSTATIC PRESSURE ON THE THERMAL CONDUCTIVITY OF SUBOCEANIC MATERIALS RECOVERED DURING LEG 128, JAPAN SEA ${ }^{1}$
}

\author{
Hajimu Kinoshita ${ }^{2}$
}

\begin{abstract}
Thermal conductivity of soft and hard sedimentary materials recovered from Hole 799B drilled during Ocean Drilling Program (ODP) Leg 128 in the Japan Sea was measured under hydrostatic pressures up to $100 \mathrm{MPa}$ at room temperature. In sedimentary materials, the dependence of the thermal conductivity on pressure varies from sample to sample. Sediment fabrics and water content, as well as porosity, seem to be key factors controlling the pressure dependence, although we cannot definitely identify yet which of them is the most important factor for determining this property. Ratcliffe's estimate of pressure correction (1960) seems to be valid on average. In view of the small effect of pressure on the thermal conductivity within pressure ranges of this study, the heat flow values obtained so far from this area of the Japan Sea do not need to be corrected significantly.
\end{abstract}

\section{INTRODUCTION}

A great amount of heat flow data in the Japan Sea area has been obtained by various authors. This area is the world's best studied backarc basin from various geophysical points of view. Recent geophysical studies, including downhole seismic and electrical experiments conducted during Leg 128 , have presented more basic information needed to solve key problems of this area in terms of the physical structure of the Japan Sea backarc basin. The heat flow values and lithospheric thickness would help to constrain the formation age of the Japan Sea in view of the uncertain results of absolute age determinations of volcanic rocks from this area. Heat flow values are usually obtained by measuring the subseafloor temperature gradient and in-situ thermal conductivity. In many cases, the thermal conductivity is obtained by measuring samples on board the ship at laboratory temperature and atmospheric pressure. We are not sure if the depressurization of the specimen has a negligible effect on the thermal conductivity values.

The scope of this study is on the variation with pressure $(P)$ of thermal conductivity of selected fine-grained, homogeneous softsediment and semi-consolidated sedimentary samples from Hole 799B (2072 to $3156 \mathrm{~m}$ subsea-surface depth) drilled during Leg 128. Measurements were performed under hydrostatic pressure conditions from atmospheric to as high as $100 \mathrm{MPa}$, which is approximately equivalent to about $3200 \mathrm{~m}$ below seafloor, assuming that the 33 material density of the overlying layer is $2.5 \times 10^{3} \mathrm{~kg} / \mathrm{m}^{3}$. If a significant effect of hydrostatic pressure on the thermal conductivity of the sedimentary materials is observed, some correction to heat flow data by conventional methods must be done; for instance, for the lithospheric age estimate based on the lithospheric thermal evolution model. The present experiment aims at determining if one must correct heat flow data that are so far available from this area of the Japan Sea.

\section{METHODS}

Samples for measurement were cut out of recovered cores, with an approximate length of $10 \mathrm{~cm}$ and in a cross section of one quarter of the core. Of the 50 samples taken by shipboard scientists, 30 specimens were poorly sealed in polyethylene containers. It is likely that the plastic containers, which had some small pinholes, leaked

\footnotetext{
${ }^{\prime}$ Tamaki, K., Suyehiro, K., Allan, J., McWilliams, M., et al., 1992. Proc. ODP, Sci. Results, 127/128, Pt. 2: College Station, TX (Ocean Drilling Program).

${ }^{2}$ Earthquake Research Institute, University of Tokyo, Tokyo, Japan.
}

moisture during the two months between their sampling and reaching this author. The rest of the samples that arrived in a plastic bag were in good condition without loss of seawater. Some of the samples, however, lost their original sedimentary fabric, probably from depressurization after recovery from deep in the drilled hole. Destruction of fabric by decompression was observed after recovery of deep-sea sediment from drilled holes by this author during Deep Sea Drilling Program (DSDP) and ODP cruises. Therefore, the shipboard scientists are not responsible for the poor preservation of physically unstable sedimentary samples.

A slim hole about $1.3 \mathrm{~mm}$ in diameter was punched in good samples near the center of each quarter cross section as deep as $5 \mathrm{~cm}$, equal to the length of the needle probe (Jeager, 1958) used for the present experiment. After inserting the needle probe into this hole, the sample pieces, including the needle probe, were wrapped with a sheet of thin plastic film and coated with silicone rubber to prevent the penetration of pressure fluid during compression. For hard consolidated samples, the holes were made with machinery tools that matched the needle probe dimensions.

Needle probes (packed in a stainless sheath of $1.0 \mathrm{~mm}$ inner diameter and $50 \mathrm{~mm}$ long) were tested and calibrated beforehand in silicon grease with known thermal conductivity at room temperature. The sample with the needle probe installed was placed in a pressure vessel filled with oil. The whole sample assemblage was compressed in a cylindrical vessel that creates hydrostatic pressures up to 100 $\mathrm{MPa}$. A heater wire and a thermistor were connected to an electronic circuit controlled by a microcomputer (CPU) through a General Purpose Interface Board (GPIB, Fig. 1: Suzuki, 1988; Suzuki and Kinoshita, 1988).

\section{RESULTS}

The thermal conductivity of the samples under pressure can be measured in the same manner as the conventional needle probe method (Von Herzen and Maxwell, 1959). Briefly, the rate of increase of the probe temperature, after switching on the electric current to the heater wire in the probe, is recorded as thermistor-resistance variations every second from a digital resistivity meter connected to the controlling CPU. The rate of change of needle probe temperature values with time greater than $200 \mathrm{~s}$ increases gradually (Fig. 2). Intuitive consideration as well as simulation experiments show that this type of change might be observed within this time span of measurement, if the thermal conductivity of the materials surrounding the sample were low enough (i.e., the boundary of the relatively small sample impedes heat loss for time $200 \mathrm{~s}$ ). This rate increase might be attributed partly to the change in the thermal conductivity of the 


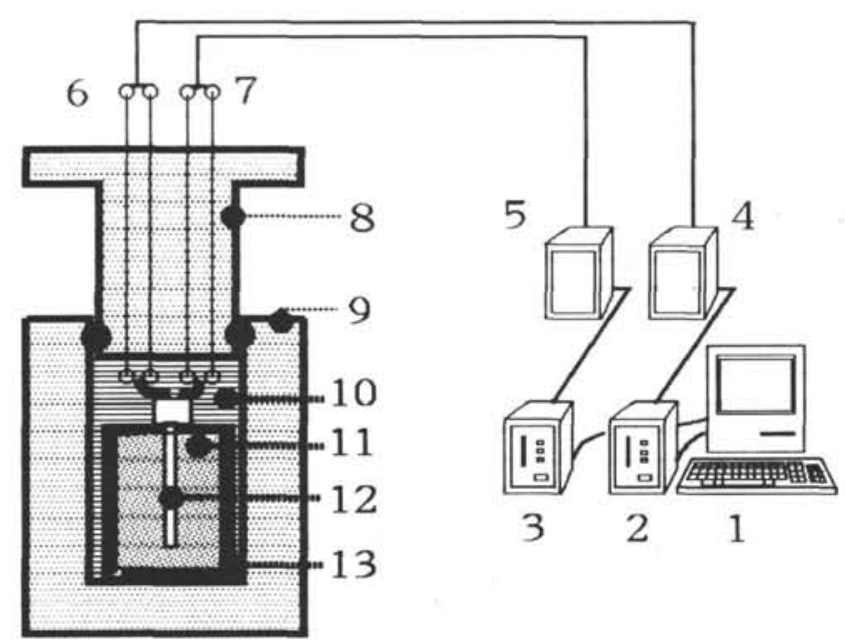

Figure 1. A schematic view of the measuring system. Desk-top computer (1) controls data acquisition (3: GPIB interface) from digital multimeter (5) connected to the thermistor (7) in the needle probe (12). Electric power to the heater (6) of the needle probe is also activated and deactivated by the computer (2: switch interface; 4 : power source). A sample (11) under pressure is inserted in hydraulic press (8: anvil, 9: cylinder) filled with high pressure oil (10). Outer shell of the sample is coated by a layer of plastic film and silicon rubber (13) as thick as $1 \mathrm{~mm}$.

sample material right next to the needle probe due to physical-chemical changes caused by heating. This is unlikely to occur because the heater wire generates only $0.0626 \mathrm{~W}$, which raises the needle probe temperature in the water-saturated samples less than $2 \mathrm{~K}$. Resistance vs. $\log t$ correlation was plotted on a computer display from the data stored in memory, and a linear portion of the needle probe temperature vs. $\log t$ curve ( $t=20$ to $150 \mathrm{~s}$ ) was selected to obtain the thermal conductivity of the material.

The final value of the conductivity is derived by applying correction factors of individual needle probe calibrations in the standard sample. There might be a slight influence of pressure on the correction factor from changes in heater and thermistor resistance with pressure. From our own experiences, however, one can safely assume that these changes for manganic heater wire and thermistors under hydrostatic pressures below $100 \mathrm{MPa}$ are very small, less than $1 \%$, which is within the limit of acceptable error. It is more likely that the needle probe, molded by plastic resin in a thin ( $1.0 \mathrm{~mm}$ inner diameter) stainless sheath, is not sensitive to pressures below $100 \mathrm{MPa}$. Therefore, the pressure effect on thermal probe characteristics is neglected in the derivation of the thermal conductivity of the sample under pressure.

Pressures exerted on the specimens ranged from 0 to $100 \mathrm{MPa}$, from which the thermal conductivity values at $30 \mathrm{MPa}$ were selected. This pressure corresponds approximately to $500 \mathrm{~m}$ below seafloor by assuming that the average density of the topmost part of sediment cover is $2 \times 10^{3} \mathrm{~kg} / \mathrm{m}^{3}$. In addition, the pressure on the sample was increased in discrete steps of $10 \mathrm{MPa}$, and this $30 \mathrm{MPa}$ is the nearest value exerted on the samples in-situ used for this study. Relative change in the thermal conductivities of the pressurized samples at $30 \mathrm{MPa}$ normalized to the thermal conductivity values at atmospheric pressure is given in Table 1 and in the histogram of Figure 3, with the semi-empirical estimate of correction factor by Ratcliffe (1960), as shown by a thick vertical bar. As a result, only 13 of the 50 total samples delivered to this author were measured successfully. Of the 13 samples, the fabric structure of three samples was considerably disturbed before measurement.

Another eight hard rock samples remain for future study at the time of this writing. Many more difficulties are anticipated in handling the hard rock samples, and more time will be needed to prepare hard rock samples for this type of experiment. Moreover, we would like to apply much higher pressures on the hard rock samples, probably

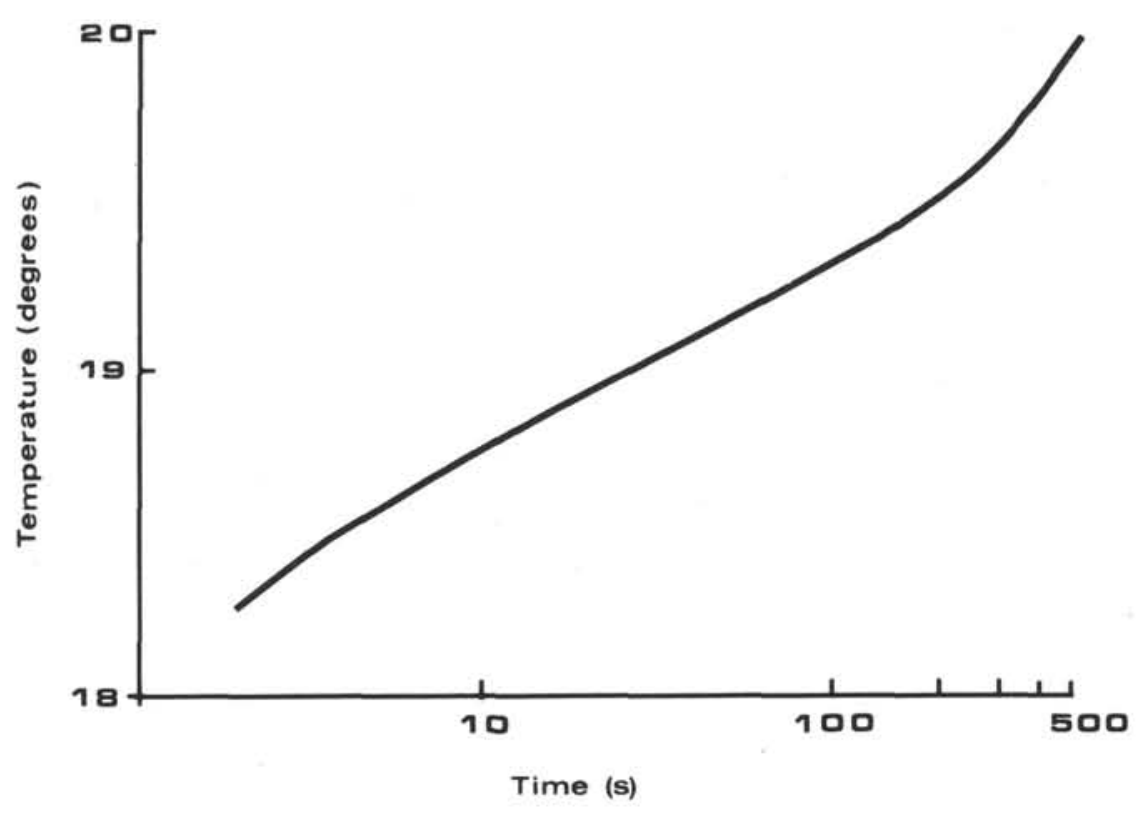

Figure 2. A typical change in temperature (T, vertical axis in degrees) vs. $\log t$ (horizontal axis in seconds) for a needle probe inserted in the pressurized specimen at $30 \mathrm{MPa}$. As the time axis in the $\log t$ scale displays higher density of data points at greater time portion, the temperature change is plotted in a continuous manner. 
Table 1. Sample numbers and relative change in the thermal conductivity.

\begin{tabular}{clccc}
\hline Sample & $\begin{array}{c}\text { Core, section, } \\
\text { interval }(\mathrm{cm})\end{array}$ & $\begin{array}{c}\text { Depth } \\
(\mathrm{mbsf})^{\mathrm{a}}\end{array}$ & $\mathrm{K}(30 \mathrm{MPa}) / \mathrm{K}(1 \mathrm{~atm})^{\mathrm{b}}$ & Remarks \\
\hline 1 & $6 \mathrm{R}-3,119-125$ & 500 & 1.018 & \\
2 & $8 \mathrm{R}-2,3-44$ & 515 & 1.174 & \\
3 & $12 \mathrm{R}-1,0-57$ & 550 & 1.033 & \\
4 & $17 \mathrm{X}-\mathrm{CC}, 0-10$ & 600 & 1.250 & \\
5 & $25 \mathrm{R}-1,116-122$ & 680 & 1.019 & \\
6 & $31 \mathrm{R}-1,67-73$ & 735 & 1.010 & \\
7 & $32 \mathrm{R}-1,20-25$ & 745 & 1.086 & \\
8 & $34 \mathrm{R}-2,19-26$ & 765 & 1.109 & \\
9 & $36 \mathrm{R}-1,142-149$ & 780 & 1.018 & \\
10 & $49 \mathrm{R}-1,40-47$ & 910 & 1.019 & \\
11 & $56 \mathrm{R}-2,88-96$ & 980 & 0.977 & \\
12 & $64 \mathrm{R}-1,4-10$ & 1055 & 1.031 & \\
13 & $67 \mathrm{R}-2,77-84$ & 1075 & 1.044 & \\
\hline
\end{tabular}

Note: $\mathrm{K}(30 \mathrm{MPa}) / \mathrm{K}(1 \mathrm{~atm}), \mathrm{K}(30 \mathrm{MPa})$, and $\mathrm{K}(1 \mathrm{~atm})$ denote the thermal conductivity at $30 \mathrm{MPa}$ and at $\mathrm{I}$ atmospheric pressure.

"Approximation.

${ }^{\mathrm{b}}$ Atmospheric pressure.

several $100 \mathrm{MPa}$, which may induce a conceivable change, but one less related to the heat flow correction. This author is preparing another set of experimental tools for testing hard rock samples. Therefore, the results on hard rock samples offered from Leg 128 will be presented at a later opportunity.

\section{DISCUSSION}

Other data previously obtained by this author show a similar tendency in pressure (i.e., a slight increase of thermal conductivity under hydrostatic pressure of $30 \mathrm{MPa}$ (Suzuki, 1988; Suzuki and Kinoshita, 1988)). It is likely that the initial compression (0-10 MPa) of the sedimentary material induces a relatively large change in the thermal conductivity, compared with the change at higher pressures. This might have been caused mainly by initial compaction of the porous materials, which produces better contact among solid particles, as suggested by Ratcliffe (comparison between copper and sand powders, 1960). A simple model of the closing of pores within the compressed sample can explain fairly well the hyperbolic increase of thermal conductivity with pressure (Suzuki and Kinoshita, 1988). This type of change is usually observed by changes in the sonic velocity of pressurized porous materials, which show a rapid increase of velocity value in lower pressure ranges.

The results of this study show that squeezing of the sedimentary materials increases the thermal conductivity. The rate of increase in the conductivity with pressure is widely variable from sample to sample. The heat flow values obtained by measuring using conventional methods are based upon thermal conductivity of sedimentary materials measured at atmospheric pressure and then corrected for total water depth. One can take the relative thermal conductivity change at pressures from 0 to $30 \mathrm{MPa}$, which is almost equivalent to 500 mbsf in Hole 799B, and compare it with the semi-empirical correction factor inferred from Ratcliffe (1960). The empirical correction factor differs only a little from the main clustering of the

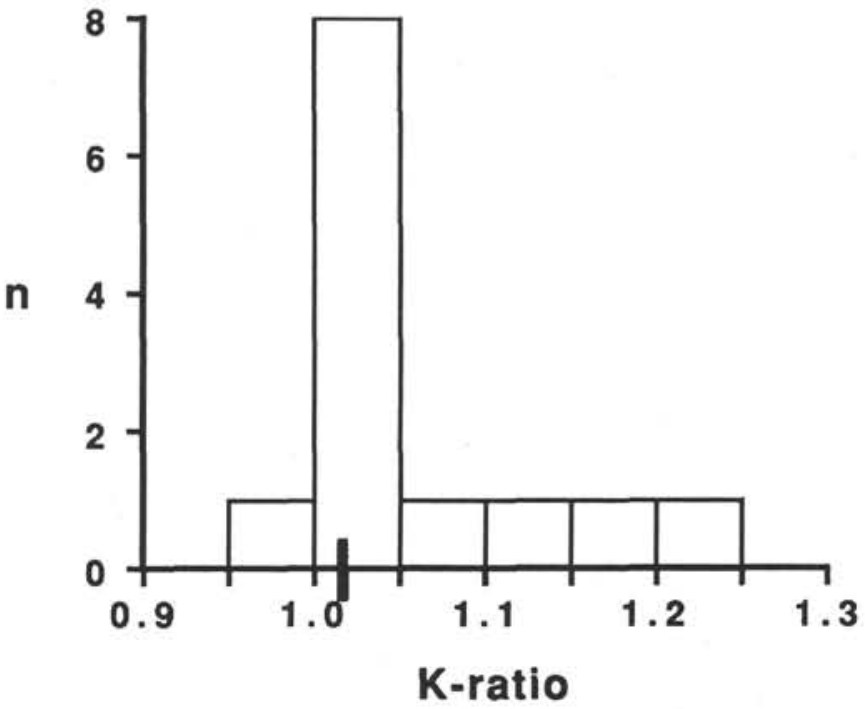

Figure 3. Histogram of number of samples vs. relative change in the thermal conductivity from 1 atmospheric pressure to $30 \mathrm{MPa}$ (K-ratio, refer to Table 1). Correction factor at $30 \mathrm{MPa}$ (corresponding water depth $=$ about $3000 \mathrm{~m}$ ), as described by Ratcliffe (1960), is shown by a thick bar.

pressure change in the present experiment. Therefore, the value of the in-situ thermal conductivity, corrected according to Ratcliffe, may be used until further definitive conclusions can be reached from more detailed studies.

\section{ACKNOWLEDGMENT}

The author is obliged to M. Makita, Chiba University, for his assistance in conducting part of the measurements of samples under hydrostatic pressures. He also helped the author to refine some parts of the measuring systems.

\section{REFERENCES}

Jeager, J.C., 1958. The measurement of thermal conductivity and diffusivity with cylindrical probes. Trans. Am. Geophys. Union, 9:708-710.

Ratcliffe, E.H., 1960. The thermal conductivity of ocean sediments. J. Geophys. Res., 5:1535-1541.

Suzuki, K., 1988. Thermal conductivity of marine sediments-dependence on pressure [Rept. for B.S.]. Chiba Univ.

Suzuki, K., and Kinoshaita, H., 1988. Effect of hydrostatic pressure on the thermal conductivity of oceanic sediments. J. Seismol. Soc. Jpn., 41:1267-1269.

Von Herzen, R.P., and Maxwell, A.E., 1959. The measurement of thermal conductivity of deep-sea sediments by a needle-probe method. J. Geophys. Res., 65:1557-1563.

Date of initial receipt: 18 March 1991

Date of acceptance: 28 February 1992

Ms 127/128B-220 